\title{
Capturing The Rabbits
}

\author{
Sarah Furlan
}

University of Technology Sydney, Faculty of Arts and Social Sciences, PO Box 123, Ultimo NSW 2007, Australia. sarah.k.furlan@student.uts.edu.au

The Rabbits, written by John Marsden and illustrated by Shaun Tan, is a beautifully designed yet melancholy allegory for the 'discovery' and subsequent colonisation of Australia. With its focus on Indigenous Australian history, Marsden has managed to summarise much of the Australian colonisation process in just 229 words. Since it was first published in 1998, the picture book has won multiple awards and continues to be a relevant text, with the issues depicted throughout still significant in Australia's contemporary social and political spheres.

Written from the perspective of the colonised, which are the marsupial-like native animals, both Marsden's writing and Tan's illustrations work together harmoniously to create an image of the two parties involved and their differing objectives. The phrase 'Might $=$ Right' appears throughout the book after the rabbits, or in our reality, the British, have colonised the country and taken full control. Although the book doesn't exhibit any obvious political judgments in its wording, this phrase alludes to the attitudes of the British settlers, regarding why they decided to colonise Australia in the way they did. With their suits, mechanical technology and musket-like weapons, the rabbits are shown to be civilised, sophisticated and intelligent. Regarding colonial history, it's well known that the British considered themselves as superior to the Aboriginal Australians, with their 'assumptions about what was 'natural' and 'proper' and 'good', according to Goodall (1995, p. 63). These preconceived assumptions are apparent within the book, as the rabbits seem to believe that their power, or their 'might', gives them the right to ignore the 'uncivilised' ways of the native marsupials and to therefore do what they like with the land. This is evident when Marsden writes, 'But our old people warned us: be careful. They won't understand the right ways. They only know their own country.' This sense of white superiority is what leads to the degradation and destruction depicted later within the book.

It could be said that Marsden, who is a non-Indigenous Australian, has unknowingly adopted some of these patriarchal attitudes himself. Although he hasn't detracted from any part of Aboriginal and Torres Strait Islander history, but rather respected and honoured it, he has told 
a story which is ultimately not his own. In doing so, he has prevented this community from telling their narrative in their own unique way. As Reynolds stated, there are "those who saw Aborigines as a form of 'fallen humanity' who could be 'morally and intellectually rescued through the civilising influence of white pedagogic institutions' (Morris 1992, p. 74). Postcolonisation, this 'white saviour' complex allowed the British to justify their damaging actions, such as the removal of Aboriginal Australian children. Indigenous Australians were left with a lack of agency and sovereignty as a result. In writing The Rabbits, Marsden has unfortunately allowed for the exclusion of an Indigenous Australian voice, one that should have the right to tell their own history.

Whilst being labelled as a picture book, one must ask the question: is The Rabbits actually appropriate for children? The book is undoubtedly brimming with distressing, complex and sometimes controversial issues surrounding the marsupials and the rabbits, no matter how subtle their presentation might be. Its intricate and brightly coloured illustrations surely appeal to children, but its dark themes may be troubling to some, especially those who have no prior knowledge about the colonisation of Australia. An example of this is the page dedicated to the Stolen Generations. The words 'And stole our children' are blasted across the page, the red ink dripping from the rabbits' quills, perhaps symbolising blood. Above, young marsupials are trapped in boxes as they are flown through the air, away from what are presumed to be their parents, whose raised arms and upturned faces are distressing to see. The illustration is powerful enough to evoke a sense of grief within the reader. Without any background knowledge, this would be difficult for a child to comprehend.

Tan argues that picture books, and his books specifically, are not only for children, but for 'anyone who reads and looks' (2001, p. 9). He states that the 'simplicity' of picture books doesn't 'exclude sophistication or complexity', and that they are a medium which everyone can enjoy and learn from, as adults are also interested in imaginative ways of thinking, seeing and interacting (Tan 2001, p. 4). So, whilst the themes portrayed within The Rabbits may be very serious, it does not mean that the book cannot be used as a reflective piece for more mature readers, or for children who are accompanied by their parents perhaps, who can help them navigate the issues depicted. I believe that it is important for Australian children, no matter their age, to learn about the history of Australia and the injustices that occurred. A gentle way to do that can be by presenting the knowledge in the format of a picture book, where the images can provide some extra guidance.

The final pages of The Rabbits paint a picture of the consequences of colonisation. Some critics, such as Bradford, have argued that the marsupials are presented here as 'primitive victims incapable of assuming agency in their own interests, unable to adjust or adapt to new and troubling times' (Collins-Gearing \& Osland 2010). For example, on one page, three marsupials are shown to be homeless within the new city, surrounded by cardboard boxes, bottles, and rabbits, who are rushing around. On another page, one marsupial seems to be locked out of the city, with its body curled up on the ground amidst the now brown and desolate land. These images are not evocative of the whole Indigenous population in Australia. As Marsden and Tan didn't include any instances of Indigenous Australian 
activism or protest, which we know has historically occurred, much of the community has been unfairly generalised within the book.

Despite this, the end of the book has been left open for the reader's reflection. The last page features both a rabbit and a marsupial sitting across from each other, staring at one another under the night sky. It looks as though the two animals are acknowledging, and more importantly, understanding each other. This mutual recognition evokes thoughts of a reconciliation between Aboriginal Australians and non-Indigenous Australians, something which has not completely been achieved yet in our country. Here, this rabbit seems to have reached a point where it understands the damage its species has caused to the land, the marsupials, and even themselves, yet it's unsure of how to fix it. As a result, the haunting uncertainty of the book's last words still ring true: 'Who will save us from the rabbits'?

\section{References}

Collins-Gearing, B. \& Osland, D. 2010, 'Who will save us from the rabbits?: rewriting the past allegorically', The Looking Glass: New Perspectives on Children's Literature, vol. 14, no. 2, viewed 15 April 2019, <http://www.lib.latrobe.edu.au/ojs/index.php/tlg/article/view/227/225>.

Goodall, H. 1995, 'New South Wales', in A. McGrath (ed.), Contested Ground: Australian Aborigines Under the British Crown, Allen \& Unwin, St. Leonards NSW, pp. 55-120.

Marsden, J. \& Tan, S. 1998, The Rabbits, Hachette Australia, Sydney.

Morris, B. 1992, 'Frontier Colonialism as a Culture of Terror', Power, Knowledge and Aborigines, La Trobe University Press in association with the National Centre for Australian Studies, Monash University, Bundoora, Vic., pp. 72-87.

Tan, S. 2001, 'PICTURE BOOKS: Who are they for?', paper presented to the Joint National Conference of the Australian Association for the Teaching of English and the Australian Literacy Educators' Association, Hobart, Tasmania, 12-15 July. 